\title{
Histomorphology and Scanning Electron Microscopy of the Gut-Associated Lymphoid Tissue in Rectum of Goats
}

\author{
V.R. Indu ${ }^{1 *}$, K.M. Lucy ${ }^{2}$, J.J. Chungath ${ }^{1}$, N. Ashok ${ }^{3}$ and S. Maya ${ }^{1}$ \\ ${ }^{1}$ Department of Veterinary Anatomy, College of Veterinary and Animal Sciences, \\ Mannuthy-680651, India \\ ${ }^{2}$ Controller of examinations, KVASU, ${ }^{3}$ Director Academics \& Research, KVASU, \\ Pookode-673 576, India \\ *Corresponding author
}

\begin{abstract}
A B S T R A C T
Gross, histological and scanning electron microscopic studies were conducted on the gutassociated lymphoid tissue (GALT) in the rectum of six crossbred male goats of six

Keywords

Goats, Histology,

Morphology, Rectal

Patch, Scanning

electron microscopy

Article Info

Accepted:

10 September 2018

Available Online:

10 October 2018

months of age. The patches forming GALT in the rectum called RC patch was seen in the rectal sinus along the whole intestinal circumference near the anorectal junction. Histologically, the lymphoid nodules in all the patches of large intestine occurred in two morphologically different forms, viz. propria nodules and lymphoglandular complexes (LGC). In the case of propria nodules, the lymphoid nodules were seen mainly in the lamina propria and its dome projected into the lumen of the intestine. In the LGC, several lymphoid nodules were almost completely located under the muscularis mucosae in the tunica submucosa. The dome was covered by a follicle-associated epithelium (FAE). The diameter of the lymphoid nodules and number of lymphocytes per nodule were $894.17 \pm 2.39 \mu \mathrm{m}$ and $41133.33 \pm 244.15$ respectively in RC patch. In scanning electron microscopy of GALT in the large intestine, the rounded sac-like follicles were the largest in the RC patch. Maximum development of lymphoid tissue was noticed in the rectal patches, suggesting that they could be exploited as targets for rectal vaccines for the induction of mucosal immune response in this species.
\end{abstract}

\section{Introduction}

The gut-associated lymphoid tissue (GALT) seen in the gastrointestinal tract is one of the largest lymphoid organs in the body. It consists of jejunal Peyer's patches (JPP) and ileal Peyer's patches (IPP) in the small intestine and isolated lymphoid follicles (ILF) and patches in the large intestine (Tenorio and Pabst, 2006). Though extensive research work has been done on the JPP and IPP in small intestine a perusal of literature revealed only few studies on the GALT in large intestine of goats.

A thorough knowledge of the histological structure of GALT is very essential since the rectal patch is an effective site for induction of systemic and local immunity by rectal vaccination and tissues from it also form valuable clinical material for diagnostic investigations of infectious diseases. 


\section{Materials and Methods}

Six crossbred male goats of six months of age were used for the present study. Animals were slaughtered after recording the body weight and the large intestines were carefully separated out, straightened and opened at the side of mesenteric attachment. Thereafter it was cleaned by washing gently in tap water after removing the ingesta and tissue pieces were collected from the rectum in the large intestine. To identify the patches clearly, the intestine from one animal was prepared according to the method described by Carlens (1928). The whole intestine was opened along mesenteric attachment and after gentle washing with cold water; it was fixed in 1 per cent acetic acid for $12 \mathrm{~h}$. Surface area of the rectal patches collected was measured by tracing their outline in a graph paper.

The tissue pieces collected were then fixed in 10 per cent neutral buffered formalin. The materials were processed routinely to obtain 5 $6 \mu \mathrm{m}$ thick serial paraffin sections and were stained by Haematoxylin and Eosin (Luna, 1968) Gomori's rapid one step trichrome method for collagen fibres (Luna, 1968), Verhoeff's method for elastic fibres (Singh and Sulochana, 1996) and Gordon and Sweet's method for reticular fibres (Bancroft and Gamble, 2003). The micrometry was done in the histological sections in six randomly selected fields under high or low power magnifications using an ocular micrometer. The morphometric and micrometric data were analysed statistically as per the methods described by Snedecor and Cochran (1994) using software (SPSS version, 21).

For scanning electron microscopy samples were fixed in 2.5 per cent gluteraldehyde in $0.1 \mathrm{M}$ phosphate buffer (PBS) $(\mathrm{pH}$ 7.2) for 24 $\mathrm{h}$ at $4^{\circ} \mathrm{C}$ and post fixed in two per cent aqueous osmium tetroxide for four hours. Thereafter the samples were processed and scanned under Scanning Electron Microscope (SEM-Model: JEOL-JSM 5600) at required magnifications at Ruska Labs, College of Veterinary Science, Sri Venkateshwara Veterinary University, Rajendranagar, Hyderabad, Andhra Pradesh.

\section{Results and Discussion}

The gut-associated lymphoid tissue (GALT) seen in the rectal sinuses along the whole intestinal circumference near the anorectal junction in all the animals studied was referred to as the rectal patch (RC patch) (Fig. 1). Similar observations were recorded by Liebler et al., (1988) and Tenorio and Pabst (2006) in calves. The per cent contribution of surface area of RC patch to the total surface area of large intestine was $1.01 \pm 0.01$. Liebler et al., (1988) observed that the RC patch formed 2.4 per cent of large intestine, up to two months of age in calves. The variation seen in the present study might be because of the difference in species.

In histologic sections the lymphoid nodules in all the rectal patches of large intestine occurred in two morphologically different units, viz. propria nodules and lymphoglandular complexes (LGC). In the case of propria nodules, the lymphoid nodules were seen mainly in the lamina propria and consisted of one germinal centre with a cap of corona and dome which projected into the lumen of the intestine at a slightly lower level than the regular large intestinal ridges. The dome was covered by a follicle-associated epithelium (FAE) (Fig. 2). In the LGC, several lymphoid nodules with germinal centres and corona were almost completely located under the muscularis mucosae in the tunica submucosa (Fig. 3). From the lining epithelium of the intestinal lumen, crypts penetrated the muscularis mucosa deep into the lymphoid tissue and branched into numerous smaller diverticula in it. 
Fig.1 Large intestine cut open longitudinally to show rectal patch (Acetic acid fixation)

1. Rectal Patch

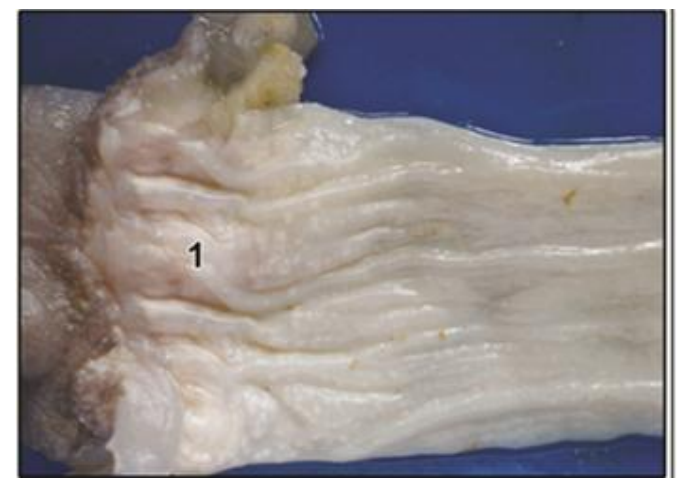

Fig.2 C.S. of rectal patch showing propria nodule. H\&E x 200

1. Follicle associated epithelium

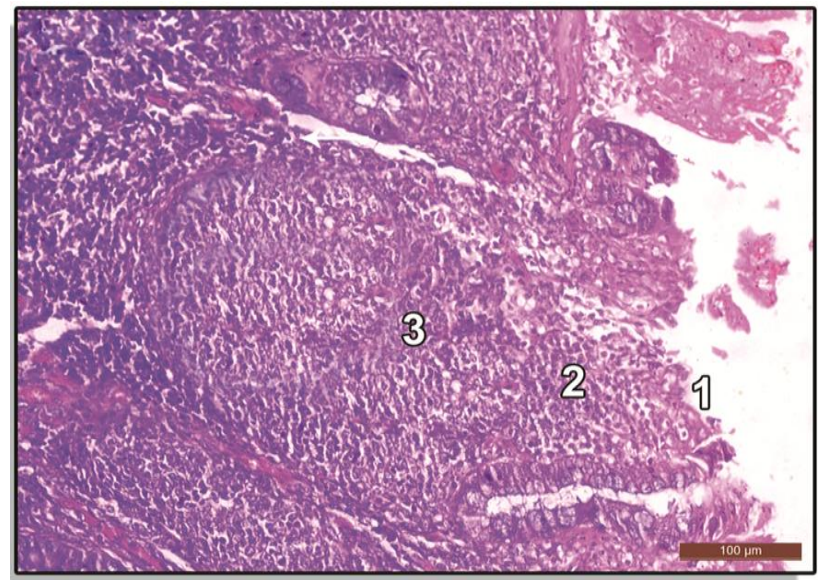

2. Dome

3. Propria nodule

Fig.3 C.S. of rectal patch showing lympho-glandular complexes. H\&E x 200

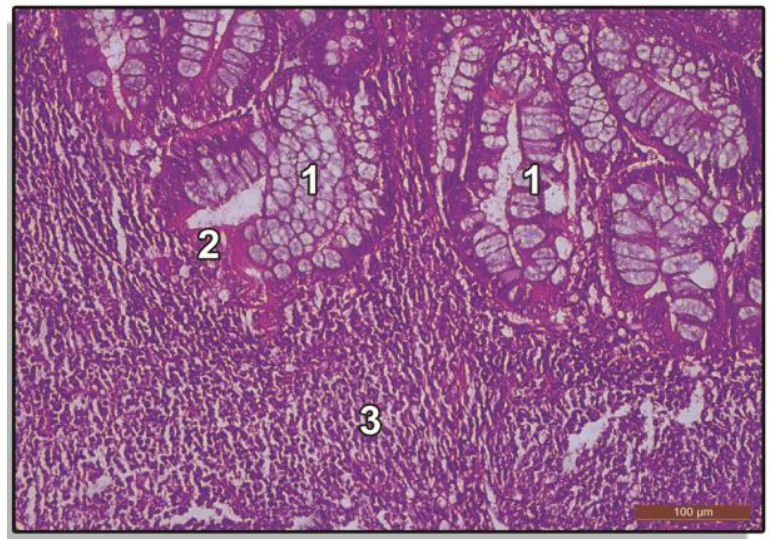

1. Branching crypt

2. Dome covered by Follicle associated epithelium

3. Lymphoid tissue 
Fig.4 Ultramicroscopy of rectal patch showing propria nodules. SEM x 500

1. Dome

2. Flattened ridges

3. Lymphocytes

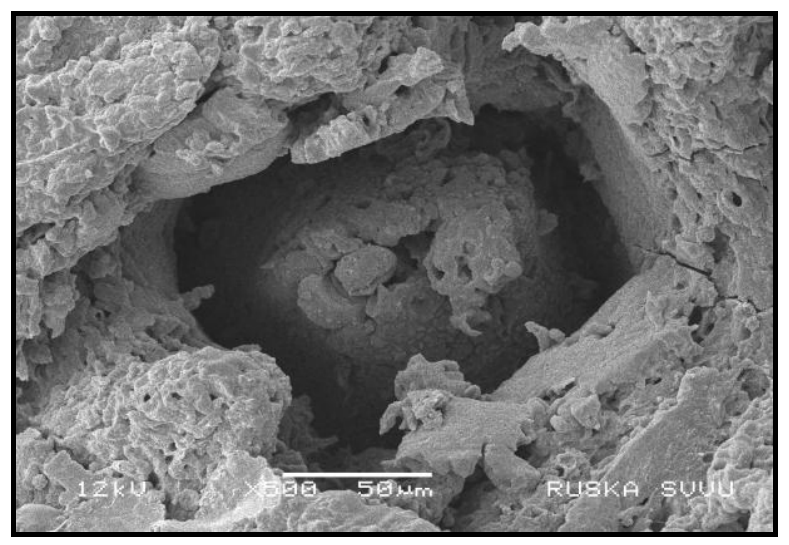

Fig.5 Ultramicroscopy of rectal patch showing submucosal lymphoid nodules. SEM x 70

1. Mucosa

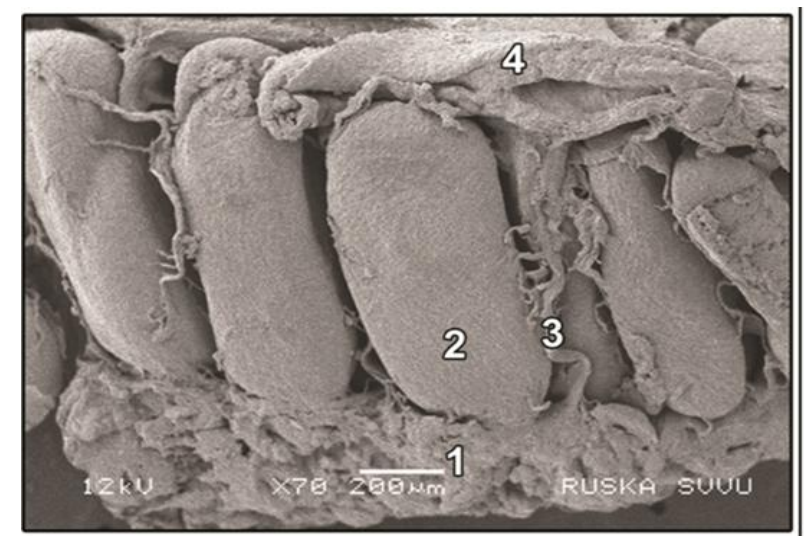

2. Lymphoid nodules

3. Blood vessels

4. T. muscularis

A small dome covered by FAE was seen in the centre of the lymphoid tissue which did not project into the intestinal lumen. The FAE consisted of single layer of thinner and shorter columnar cells, numerous intraepithelial lymphocytes, a few enterocytes and lack of any goblet cells. Similar observations were made by Leibler et al., (1988) in calves, and Gautam et al., (2013) in goats. The lymphocytes within the dome were tightly packed, relatively larger with large nuclei and stained lighter than the distinct corona of lymphoid nodules below it. These results are in accordance with the observations made by Leibler et al., (1988) and Tenorio and Pabst (2006) in calves.

In the present study, the lymphoid nodules were rounded or pear-shaped in the rectal patches as observed by Leibler et al., (1988) in calves. The average nodular count per field under low power magnification of microscope remained about one to two (Fig. 2). The diameter of the lymphoid nodules and number 
of lymphocytes per nodule $894.17 \pm 2.39 \mu \mathrm{m}$ and $41133.33 \pm 244.15$ respectively in $\mathrm{RC}$ patch (Fig. 3). Similar reports on micrometry of the lymphatic nodules of patches in the large intestine are not available for comparison. The lymphoid nodules were surrounded by submucosal connective tissue capsule formed of collagen, reticular and a few elastic fibres and blood vessels. These observations tally with the findings of Leibler et al., (1988) in calves and Gautam et al., (2013) in goats. The internodular region in all the animals under study showed a few HEVs, plasma cells and small and large lymphocytes as noticed by Tenorio and Pabst (2006) in calves. In Scanning Electron Microscopy (SEM) of RC patch in the large intestine, the mucosa was characterized by flattened ridges separated by furrows. In between the ridges, dome of the propria nodules were visible (Fig. 4). In cut sections below the dome epithelium, rounded sac-like follicles with interfollicular area between them were seen. These observations concur with the reports of Liebler et al., (1988) in calves (Fig. 5).

In goats maximum development of lymphoid tissue was noticed in the rectal patches, suggesting that they could be exploited as targets for rectal vaccines for the induction of mucosal immune response in this species.

\section{References}

Bancroft, J.D. and Gamble, M. 2003. Theory and Practice of Histological
Techniques. $\quad\left(5^{\text {th }} \quad\right.$ Ed.). Churchill Livingstone, New York, 796p.

Carlens, O. 1928. Studies on the lymphoid tissue of the intestine in some domestic animals. Z. Anat. Entwicklungsgesch. 86: 393-493.

Gautam, C.K., Talukdar, M., Sarma, K., Sarma, S., Barman, N.N. and Baishya, G. 2013. Distribution and histomorphology of solitary lymphoid nodules of large intestine in indigenous goat of Assam (Capra hircus). Indian Vet. J. 90: 18-20.

Liebler, E.M., Pohlenz, F. and Cheville, N. 1988. Gut-associated Lymphoid Tissue in the Large Intestine of Calves. Vet. Pathol. 25: 509-515.

Luna, L.G. 1968. Manual of Histological Staining Methods of the Armed Forces Institute of Pathology. ( $3^{\text {rd }}$ Ed.). Mc Graw-Hill Book Company, New York, $258 \mathrm{p}$.

Singh, U.B. and Sulochana, S. 1996. Handbook of Histological and Histochemical Techniques. Premier Publishing House, Hyderabad, 111p.

Snedecor, G.W. and Cochran, W.G. 1994. Statistical Methods. ( $9^{\text {th }}$ Ed.). The Iowa state university press, USA, 313p.

Statistical Product and Service Solutions (SPSS) Statistics for Windows, Version 21.0. Armonk, NY: IBM Corp

Tenorio, E.M.L. and Pabst, R. 2006. MALT structure and function in farm animals. Vet. Res. 37: 257-280.

\section{How to cite this article:}

Indu, V.R., K.M. Lucy, J.J. Chungath, N. Ashok and Maya, S. 2018. Histomorphology and Scanning Electron Microscopy of the Gut-Associated Lymphoid Tissue in Rectum of Goats. Int.J.Curr.Microbiol.App.Sci. 7(10): 958-962. doi: https://doi.org/10.20546/ijcmas.2018.710.106 